\title{
Nurses are Key Members of the Abortion Care Team: Why aren't Schools of Nursing Teaching Abortion Care?
}

\author{
Martha Paynter ${ }^{1}$, Dr. Wendy Norman ${ }^{2}$, \& Dr. Ruth Martin-Misener ${ }^{1}$ \\ ${ }^{1,3}$ Dalhousie University School of Nursing, Halifax, Nova Scotia. \\ ${ }^{2}$ University of British Columbia School of Nursing, Vancouver, British Columbia
}

Cite as: Paynter, M., Norman, W. \& Martin-Misener, R. (2019). Nurses are Key Members of the Abortion Care Team: Why aren't Schools of Nursing Teaching Abortion Care? Witness: The Canadian Journal of Critical Nursing Discourse, 1(2), 17-29 https://doi.org/10.25071/2291-5796.30

\begin{abstract}
Abortion is a common and safe procedure in Canada, with the Canadian Institute for Health Information reporting approximately 100,000 procedures per year. Yet access remains problematic. As abortion is unrestricted by criminal law in Canada, access is limited by geographic barriers and by a shortage of providers. We present a feminist critical lens to describe how the marginalization of nursing and nurses in abortion care contributes to social stigma and public misunderstanding about abortion access. The roles of registered nurses and nurse practitioners in abortion advocacy, service navigation, counselling, education, support, physiological care and follow up are underutilized and under-researched. In 2015, decades after its availability elsewhere in the world, Health Canada approved mifepristone (a pill for medical abortion). In 2017, provincial regulators began to authorize nurse practitioners to independently provide medical abortion care, as appropriate given the inclusion in nurse practitioner scope of practice to order diagnostic tests, make diagnoses, and treat health conditions. Ensuring nurse practitioners are able to practice medical abortion has the potential to significantly increase abortion access for rural, remote and other marginalized populations. There is also an opportunity to optimize the registered nurse role in abortion care. However, achieving these improvements is challenging as abortion is not routinely taught in Canadian Schools of Nursing. We argue that to destigmatize abortion and improve access, undergraduate nursing and nurse practitioner programs across the country must begin to include abortion and family planning competencies.
\end{abstract}

Keywords: Abortion, Nursing Education, Access, Feminist Analysis, Canada

\section{Introduction}

Canada is one of the only countries in the world to have completely decriminalized abortion (Kishen \& Stedman, 2010; World Health Organization, 2018). It is a common procedure:
97,764 abortions were recorded in 2016 (Canadian Institute for Health Information [CIHI], 2016) compared to 376,291 total live births that same year (Statistics Canada, 2017). It is estimated that between one quarter to one third of women globally will obtain an abortion in their

Corresponding Author: Martha Paynter, Dalhousie University School of Nursing, PO Box 15000, Halifax, Nova Scotia B4J4R2, mpaynter@dal.ca 
lifetime (Sedgh et al., 2016) and 31\% of women in Canada have had at least one abortion (Norman, 2012). In general, Canadian abortion providers feel safe in their work (Norman et al., 2016). In the past fifty years abortion has become ever-more available in Canada, with significant improvements in access made possible through regulatory changes since 2014. Despite these shifts, barriers to access remain. Canada is a large country, with most abortion providers located in major urban centres. Changes in Canadian regulations that improve abortion access are occurring at the same time as restrictions in the United States are limiting abortion access. This may cause confusion for Canadian public and clinicians that could result in misinformation, delays and barriers to care. We use a critical lens informed by feminist standpoint theory (Harding, 1992) to examine the underutilized and underresearched role of nurses in abortion provision. The subordination of everyday experiences of women seeking abortion and women working as nurses in abortion care is not neutral in its impact on health services, research and policy. We argue that normalizing abortion and family planning care in nursing education is an important underutilized strategy to improve access to high quality abortion care in Canada.

In Canada, abortion was first decriminalized in 1969, when the Liberal federal government at the time passed amendments to the Criminal Code to permit abortion in hospitals if a therapeutic abortion committee comprised of physicians determined the procedure was necessary to prevent harm to the patient. In 1969, Dr. Henry Morgentaler, a Holocaust survivor, family physician, and the leading legal and clinical activist for abortion access in Canada for decades, opened the first free-standing clinic for elective abortions. Refusing to seek approval from a committee of physicians before performing abortions, the clinic's operations directly violated what was then Section 251 of the Criminal Code (McFadden, 2013). Dr. Morgentaler was charged and tried several times in the 1970s and imprisoned a total of ten months.
In 1982, Canada legislated the Constitution Act, which enshrined the Charter of Rights and Freedoms to protect human rights. Section 7 of the Constitution prohibits violations to life, liberty and security of the person (Government of Canada, 1982). It was under this section that, in the 1988 landmark R v. Morgentaler Supreme Court of Canada decision, the criminal law restricting access to abortion was deemed unconstitutional and was struck down $(\mathrm{R} v$ Morgentaler, [1988] 1 SCR 30). Abortion has since been considered a clinical procedure governed by health professional regulations and not criminal law (Shaw \& Norman, 2019).

We aim to demonstrate, using a feminist perspective, how the historical narrative of abortion access in Canada, which has focused on physicians providing surgical abortion and leading the political fights for access, has contributed to the marginalization of nursing in abortion care. Although abortion is common, nursing education has not kept pace with the changes in abortion care and has failed to provide for commensurate abortion and family planning priorities in nursing education. We argue that by addressing the latter, we may address the former.

A feminist standpoint acknowledges how sex and gender norms, stereotypes and discrimination limit and circumscribe not only individual experiences but also social structures and institutions, such as regulatory regimes, clinical care, research, and health professional education. Nursing is a female-dominated profession operating in a medical hierarchy that is built from and reinforces gender inequity, with medicine perceived as "knowing more" and nursing as "second best" (Price, Doucet \& McGillis Hall, 2014, p.105). Despite the development of nursing into a dynamic, skilled and academic profession, nursing continues to face stereotypes of being "morally superior" to medicine as well as having a "monopoly on caring" (Price, Doucet \& McGillis Hall, 2014, p. 106). Although nurses do play increasingly visible and important roles in advocacy in Canada (Avolio, 2014), nurses continue to be thought first as bedside care providers and not as leading the charge for 
political change. Furthermore, the historic foundation of Canadian nursing in Christian religious orders (Baker, Guest, Jorgenson, Crosby, \& Boyd, 2012) creates persistent tension with leadership in advocacy for abortion and family planning from the nursing profession.

Although most abortion patients are women (girls, trans, nonbinary and Two Spirit people also require abortion care), they have rarely acted in the lawsuits challenging abortion access in Canada. This is likely due to fear of stigma, violence, and even criminalization. Indeed, laws governing abortion in Canada have shifted most significantly due to failed prosecution of physicians, specifically Dr. Henry Morgentaler. In defiance of Section 251, Morgentaler opened clinics in several provinces and was tried and acquitted in both Quebec and Ontario (The Canadian Press, 2009). Another key case also centred on men: In Trembly v. Daigle [1989] 2 S.C.R. 530, a male partner (Jean-Guy Tremblay) accused of abuse of a pregnant woman (Chantal Daigle) sought an injunction to prevent her from obtaining an abortion. Daigle obtained the abortion in the United States while the case was ongoing; the Supreme Court ruled in the case that the fetus did not have rights and, furthermore, partners do not have rights to prevent abortions. With important implications for women's rights, the impetus for the case was a man's sense of entitlement.

By contrast, women have played key roles in litigation for abortion access in the United States. The landmark case Roe v. Wade was brought forward by a Texan woman, under the pseudonym "Roe" (Roe v. Wade, 410 U.S. 113 1973). She won the right to abortion on the United States' constitutional grounds of right to privacy. In 1976, Planned Parenthood challenged the state of Missouri's statute that a woman must receive her husband's permission to seek an abortion, and won (Planned Parenthood v. Danforth, 428 U.S. 52 [1976]). In 1980, a woman on Medicaid assistance (Cora McRae) led a class action lawsuit to challenge the exclusion of abortion from Medicaid-insured services. Although the case initially resulted in an injunction against the state, the Supreme Court later ruled that states participating in Medicaid were not required to fund abortion (Harris v. McRae, 448 U.S. 297 1980).

Canadian abortion discourse is changing. In the most recent legal dispute, a group of activists called "Abortion Access Now Prince Edward Island (AANPEI)", filed in 2016 against the province with the support of the Women's Legal Education and Action Fund. They argued the 30year unwritten ban on abortion services on PEI violated Section 7, 12 and 15 of the Constitution Act (Nijhawan \& McMillan, 2016). The Liberal provincial premier at the time, Wade MacLaughlan, conceded the lack of services on PEI was unconstitutional, and the province started on-Island abortion services the next year.

Beyond the legal disputes, physicians and surgeons dominate the regulatory control of abortion provision. Until 2017, only physicians were permitted to perform abortion in Canada. Physicians also long determined eligibility for abortion. Despite the 1988 Supreme Court ruling against Section 251 in the Morgentaler decision, until 2014 medical regulations stipulated that patients in New Brunswick required the approval of two physicians to seek a provincially funded surgical abortion in a hospital. Due to persistent activism led by mostly women volunteers of Reproductive Justice New Brunswick, that requirement became an election issue and was lifted when Premier Brian Gallant was elected in 2014 (McTavish, 2015). While in the cases of PEI and NB it was front-line activists who did the leg work, it is the men in positions of provincial government leadership that are credited with the change.

Because until 2017 only physicians were authorized to perform abortions, physician location and willingness to provide abortion has shaped access. Until recently, upwards of $95 \%$ of abortions in Canada were surgical and took place in a small number of clinics mostly in large urban settings (Norman et al., 2016). In 2012, there were a total of 94 abortion facilities and 270 individual abortion providers across the entire 
country (Norman et al., 2016). Rural, remote, low-income and otherwise marginalized populations faced geographic and socioeconomic barriers to access. As a result, access in Canada has been highly unequal because there are few providers located in few locations. Policies to reduce clinical restrictions and/or improve provider remuneration are likely to reduce individual barriers to providers adopting abortion into their practices. One such policy change was that of the federal drug regulator, Health Canada, which recently approved the gold standard medication for medical abortion, mifepristone.

In 2015, decades after its availability in other jurisdictions, Health Canada approved mifepristone for use in medical abortion in Canada (Health Canada, 2015b; Health Canada, 2015a; Health Canada Drug Product Database, 2015). Unlike surgical services, which must be conducted in an appropriate accredited procedural facility, mifepristone allows abortion provision to shift to primary care responsibility. It is self-administered, in the patient's home. Globally, this new access to medical abortion is challenging the traditional enforceability of restricted legal and professional regulation of abortion provision and shifting the experience towards self-management. The rhetoric that abortion is a "decision between a woman and her doctor", once considered a rallying cry for the pro-choice movement, is challenged when, internationally, abortion pills can theoretically be accessed by anyone able to order the product online and receive it by mail (Aid Access, 2019; Erdman, 2019).

In Canada, mifepristone is approved for use to nine weeks gestation. Prior to mifepristone availability in Canada in early 2017 , about $5 \%$ of abortions were performed using medical methods such as methotrexate and misoprostol (CIHI, 2017; Norman et al., 2016). With mifepristone on the market only two years, medical abortion has quickly already become the norm in some western areas of Canada (Grant, 2019).

Availability of medical abortion paved the way for a shift from physician-centredness in abortion discourse generally. The early discussions about mifepristone included concerns about the pharmacist role (Norman \& Soon, 2016; Vogel, 2017). At first, to prescribe and dispense it, both physicians and pharmacists were required to complete mandatory training about mifepristone, and physicians--not pharmacists--were obliged to dispense the drug and observe its administration (Health Canada, 2015b). The regulatory regime shifted quickly to allow pharmacists to dispense, patients to take the medication at home, and training to be recommended but not required (Health Canada, 2017).

With respect to the nurse role in abortion care, an important shift occurred in 2017 when provincial nurse regulators began to authorize nurse practitioners (NPs) to prescribe mifepristone as a component of independent provision of medical abortion (College of Nurses of Ontario, 2017). NPs are often the only prescriber to whom rural and remote community members have access. NPs play a key role in improving service equity across the country (Canadian Nurses Association, 2017). NP provision of mifepristone complements the portable nature of medical abortion and may support significant increases in access to abortion for underserved populations (Kishen \& Stedman, 2010). Since NP prescribing of mifepristone is new in Canada, its impact is yet to be determined.

For the first time in Canadian history NPs are now authorized by their own regulators to independently provide abortion. However, prescribing mifepristone is only one aspect of abortion care. The emphasis on the authority to prescribe can obscure the necessary role of nurses, social workers, pharmacists, administrative clerks and other health team members in holistic abortion care delivery.

Nursing responsibilities in abortion care include patient education, communication; physical, social and psychological assessment; counselling, education, treatment, support, comfort, monitoring, discharge and follow up (Haney, 2011). Nurses may act as navigators between services such as diagnostic imaging, serology, 
post-abortion contraception provision and social work services. They may conduct administrative tasks, develop policy or lead practice innovations, research, and advocacy.

Nurses remain under-recognized but key members of the abortion care team. During surgical abortions, nurses may be present for most of the time spent with a patient. As "Sally", an abortion nurse working at a clinic in Vancouver describes, "I'm helping women in crisis. They don't see the doctor's face during the procedure. All they see is me" (Dunphy, 2018, p. $1)$. In a volume of Canadian abortion stories edited by Stettner (2016), an unnamed patient contributor writes of her experience at a New Brunswick clinic, "Clinic staff members were supportive, respectful, and efficient. A sensible nurse held my hand and talked to me through the uncomfortable but brief procedure" (Stettner, 2016, p. 87). Patients may learn of nursing roles only after they are seeking abortion care and may be reluctant to discuss their experiences with nursing care due to stigma and secrecy about the abortion experience itself.

Nurses themselves are unlikely to realize most abortion care is provided by nurses. Abortion is not routinely taught in undergraduate nursing programs or NP programs in Canada (Sheinfeld Arnott, El-Haddad, \& Foster., 2016). Without this education, nurses may be less likely to imagine themselves working in abortion care and to seek opportunities in this field. If abortion is seen as a normal part of nursing work, nurses may be more likely to contribute to advocacy to advance abortion access and best clinical practices. From a feminist standpoint, recognizing the nursing role in abortion care can shift the dominant historical narrative in Canada from one centering physicians as political activists and surgical providers to one that positions abortion as a normal part of holistic reproductive care for a broad public, with nursing leadership in advocacy, education, research and care.

\section{Literature Review}

There is a limited body of evidence examining nurses and abortion care. The most recent systematic review of literature on this topic was published in 2011 (McLemore \& Levi, 2011). The international review included 59 studies and grouped the studies into five thematic areas: 1) legal and ethical responsibilities; 2) nurses' attitudes and perceptions; 3) non-physician clinicians providing abortion care; 4) nursing role in patient options counselling and education; and 5) physiologic care. None of the studies in this review were set in Canada.

Haney (2011) provides a historical discursive analysis of the construction of nursing identity in abortion as derived from fifty years of articles in The Canadian Nurse. She finds it is necessary to present abortion care as legitimate nursing work to enable the provision of safe abortion services. She writes, "the absence of those abortionsupportive roles or the widespread availability of identities that forbid abortion work as professional practice undermine nurses' abilities to provide and promote safe abortion care" (Haney, 2011, p. 63). The lack of nurse visibility in abortion work and of nurses seeing themselves as participating in abortion care has safety implications for the public because it results in restrictions on access.

In 2005, Carleton University student Susan Bishop presented a review of the literature on nurses who support women in second and third trimester terminations for fetal anomalies and found no studies to include. She later conducted her dissertation project by interviewing 11 nurses in Ontario providing this care (Bishop, 2007). Themes that emerged included making choices, being pulled in two directions, and riding an emotional roller coaster. These themes point to the lack of stability and certainty about nurses' responsibility in abortion provision.

Parker, Swanson and Frunchak (2014) conducted a qualitative study with 10 labour and delivery (L\&D) nurses in Quebec regarding their psychosocial, educational and administrative support needs while caring for women undergoing pregnancy termination. For the 
participating nurses, abortion care was a small part of their role in maternal health, and most of the terminations were sought for fetal anomaly. In Canada and around the world, most abortions are sought under 12 weeks gestation (CIHI, 2017; Segdh et al., 2016), when it is unlikely fetal anomaly has been detected. The themes that emerged from Parker et al.'s (2014) interviews included: needing emotional support from peers to normalize this type of care, fulfilling the nursing role, managing moral distress, developing therapeutic relationships, and maintaining healthy boundaries. They also described needing to interact with physicians strategically to meet patient needs. While rich in analysis, the findings from this study may not be transferable to the nurses providing abortion care in the first trimester context.

There is one known Canadian study exploring the experiences of nurses working in a hospital-based abortion clinic environment. Veiga et al. (2016) examined the impact of permitting a patient support person in the recovery room postprocedure. All eight nurse participants indicated the presence of a support person was not helpful, and they were concerned about the impact on patient privacy. This study begins to explore the tensions between the supports patients want and the perspectives of nurses about their responsibilities in abortion care. It points to the need to critically examine how nurses navigate their positions of power vis-à-vis the patient.

There is one known Canadian study examining nursing education on abortion. Sheinfeld et al. (2016) surveyed the 23 program directors of the 32 then-accredited Nurse Practitioner (NP) programs in Canada. They asked about coverage of abortion in didactic and/or clinical curriculum. The NP programs were graduate level and all students were Registered Nurses. Of the 16 survey respondents ( $70 \%$ response rate), $50 \%$ responded that they did not offer "pregnancy options counselling, first-trimester abortion procedures, and/or post-abortion care in the clinical curriculum" (Sheinfeld et al., 2016, p. 24) and $56 \%$ responded that they did not offer these topics in the didactic curriculum. Only two respondents describe abortion teaching as "an area of strength" (Sheinfeld, 2016, p. 24). Of those that did offer teaching on the topic, less than one hour was generally devoted to it. Notably, the reason offered for lack of teaching on abortion was that it was "not a priority", rather than for religious reasons or due to potential for controversy (Sheinfeld et al., 2016). But why would abortion, such a common experience for women, not be a priority in the training of health professionals who are largely women? From a feminist standpoint we see the need to centre women and nurses in not only the political discourse but the research and clinical education of health care providers to support access to quality abortion care.

\section{Nurses in Abortion Care in Canada}

Nurses form the largest health care workforce in the country (Canadian Nurses Association, 2013). Approximately 12,000 baccalaureate-prepared nurses graduate every year (Canadian Association of Schools of Nursing, 2017b). More than $90 \%$ of nurses are female (Canadian Nurses Association, 2018). Although it is not known how many go on to work in abortion service, nurses work in clinics, operating rooms, public health youth clinics and primary practice offices where abortions are referred, performed and prescribed. They staff the nurse hotlines in many provinces that medical and surgical abortion patients alike may call for preliminary and/or follow up questions and support. They work in emergency rooms and interdisciplinary clinics where people may first learn of unplanned pregnancy. In all these contexts nurses must be capable of providing compassionate, informed care. This care depends on access to appropriate education. Approximately $65 \%$ of abortion patients in Canada have had one or more previous deliveries (CIHI, 2017), yet the 20-page Entry to Practice Competencies for Nursing Care of the Childbearing Family for Baccalaureate Programs in Nursing (Canadian Association of Schools of Nursing, 2017a) does not include the word "abortion". 
The expansion of prescribing authority for medical abortion to NPs in some provinces the year following Sheinfeld et al.'s (2016) publication should prompt change in the patterns they observed. Not only should their survey of abortion content in the curriculum of nurse practitioner programs be repeated, it should be expanded to include undergraduate programs, and a detailed qualitative investigation of how abortion is taught.

\section{Nurses in Abortion Care in the United States}

The invisibility of the nurse role in abortion care in Canada differs in the United States. There, the student advocacy organization Nurses for Sexual and Reproductive Health (NSRH) (2019) has over 30 chapters in 20 states to advocate for the inclusion of abortion in nursing school curricula. No such organization exists in Canada. NSRH's programming includes an abortion care elective (ACE), an annual conference, and a clinical "externship" of at minimum 30 hours in an abortion clinic. Unlike in Canada, in some areas of the United States, advanced practice nurses are authorized to perform surgical abortions and such care provision has been found to be safe (Weitz et al., 2013).

The United States is a significantly different legal and regulatory context for abortion in comparison to Canada. Although legal since the Roe v. Wade ruling in 1973, the Hyde Amendment in 1977 resulted in the immediate exclusion of most abortion from Medicaid. As Medicaid provides health insurance to low-income people, such a restriction would create a class difference in access that, in Canada, would violate the Charter of Rights and Freedoms equality provision (Section 15) (Government of Canada, 1982). State laws place further limits, such as gestational age limits, requirement of a waiting period, and parental involvement (Guttmacher Institute, 2019). No provincial law in Canada restricts access to abortion care.

Abortion is adversarial in the United States, but not in Canada. While access in Canada becomes ever easier, the US has experienced 1193 legislative attempts at restricting access since 1973 (Nash, Gold, Mohammed \& Cappello, 2018). While in Canada, providers' conscientious objection is increasingly limited (Glauser, 2018), in the US, 45 state laws protect providers' right to refuse to participate in abortion (Guttmacher Institute, 2019). Although there have been attacks against abortion providers in Canada, none have been lethal, while the US has experienced at least 11 assassinations of abortion providers (Stack, 2015). A nurse named Emily Lyons survived a domestic terrorist attack on an abortion clinic in Birmingham, Alabama in 1998 (Paepcke, 2018). It is possible that the more polemic legal and regulatory regime in the United States compared to Canada has prompted or even necessitated greater organization and specific attention to nursing education about and roles in abortion.

\section{Nursing Education}

The reasons abortion is "not a priority" (Sheinfeld et al., 2015) in nursing education programs are likely complex. Although Sheinfeld et al. found it may not be religious institutional restrictions that precludes nursing schools' teaching about abortion, nursing is a historic occupation of religious orders. The religious foundation to nursing is described as stronger in Canada than in the United States (Melchior, 2004). Several schools of nursing in Canada still bear the name of saints. The influence of that history persists and is part of nursing's entanglement with feminism.

Abortion is indisputably a feminist issue, and a critical feminism examination of the invisibility of nursing roles in abortion care must consider nursing's relationship with feminism. Melchior (2004) traced the parallel historiographies of feminism and nursing in Canada over the twentieth century. The first wave of suffrage and rights-focused feminism corresponded to a celebration of the "nurturing, self-sacrificing heroine" in nursing (Melchior, 2004, pp. 351352). The second wave allowed critique of "devaluation of women's work and how that translated into a lack of status and power for nurses" (Melchior, 2004, p. 352). By the third 
wave, the theoretical grappling with the complexity of women's lives matched understandings of "complexity of the nursing experience, which went beyond gender alone" (Melchior, 2004, p. 352). The most recent evolution of feminism(s) considering the intersections of oppression and identity (Crenshaw, 1989). Intersectionality invites selfcritical examination of nursing's internal exclusions and patterns of discrimination (Van Herk, Smith \& Andrews, 2011). Indeed, this examination should include nursing attitudes and behaviours of power and domination vis-à-vis patients and families.

However, Wall (2007) writes that nurses have an aversion to theory that obscures the ability to think critically of nursing through a feminist lens and causes nurses to take for granted their status as subjects in health service, not agents. They are "likely to shy away from theory that is political" (Wall, 2007, p. 42). Nursing and nurses orient to experience, to doing. On the one hand, it is by doing abortion care and abortion education that it may be demystified, destigmatized, and depoliticized. On the other, political engagement from nursing leadership, including schools and organizations representing nursing education and nurses, is necessary to educate the next generation of nurses to be high quality abortion care providers that improve access and patients' experiences. Despite decriminalization, abortion remains politicized, and integrating knowledge of abortion into nurse training teaches political engagement as well.

\section{Moving Forward}

Nurses' contributions to abortion care are dynamic and varied, and include education, counselling, clinical care and, for NPs, independent provision of care. Medical abortion is now publicly funded in all provinces and territories, with federal funding for Nunavut (Abortion Rights Coalition of Canada, 2019). Starting with a landmark change in practice in Ontario, and now in every province and territory except Quebec, NPs are authorized to prescribe medical abortion (Association of Registered
Nurses of Newfoundland and Labrador, 2019; British Columbia College of Nursing Professionals, 2019; College and Association of Registered Nurses of Alberta, 2019; College of Nurses of Ontario, 2019; College of Registered Nurses of Manitoba, 2019; College of Registered Nurses of Prince Edward Island, 2019; Nova Scotia College of Nursing, 2019; Nurse Association for New Brunswick, 2019; Ordre des infirmières et infirmiers du Québec, 2019; Registered Nurses Association of the Northwest Territories and Nunavut, 2019; Saskatchewan Registered Nurses Association, 2019; Yukon Registered Nurses Association, 2019). In 2018, nurses at the Nova Scotia Women's Choices Clinic helped develop the hotline to centralize all abortion self-referrals across the province, which until then had required physician referrals for access to care (The Canadian Press, 2018). A similar hotline has successfully served BC since 1998 and was also developed by nursing leaders (Norman et al., 2014).

Notwithstanding these progressive developments and examples of nursing leadership, the roles of nurses in abortion care are largely invisible. Through a feminist analysis we have shown that several aspects of the Canadian context have supported this invisibility: the dominance of male physicians in litigation to decriminalize abortion; the persistent centering of physicians in regulations that followed; the religious foundation of nursing; and nursing's [aversive?] relationship with feminist theory itself.

We can begin to address the invisibility of nurses in abortion by first requiring training in the competencies appropriate for abortion care in all didactic and clinical undergraduate nursing curricula in Canada. Nurses, wherever they work in the health care system, should graduate knowing how to support patients who disclose an unwanted pregnancy, and should understand the pharmacologic and physiological processes of medical and surgical abortion. Destigmatization of abortion begins with talking about it. The nursing classroom is an opportune and necessary site for these discussions. Uptake of abortion training in schools of nursing must not rely on the 
The Canadian Journal of Critical Nursing Discourse See it. Speak it. Write it. Change it.

individual activism of students; it is the responsibility of nursing education leaders. This is the critical and necessary next step to improve access to high quality abortion and family Ethical Permissions planning care for all. 


\section{References}

Abortion Rights Coalition of Canada. (2019). List of Abortion Clinics in Canada. Retrieved from: http://www.arcccdac.ca/list-abortion-clinics-canada.pdf

Aid Access. (2019). http://aidaccess.org Association of Registered Nurses of Newfoundland and Labrador (2019). https://www.arnnl.ca/

Avolio, C. (2014). Political advocacy: Beliefs and practices of Registered Nurses (Masters thesis). Electronic Theses and Dissertations. 5064. Retrieved from: https://scholar.uwindsor.ca/etd/5064

Baker, C., Guest, E., Jorgenson, L., Crosby, K., \& Boyd, J. (2012). Ties that bind: The evolution of education for professional nursing in Canada from the $17^{\text {th }}$ to the $21^{\text {st }}$ century. Canadian Association of Schools of Nursing. Retrieved from:

https://www.casn.ca/wpcontent/uploads/2016/12/History.pdf

Bishop, S. (2005). Nurses' experiences of caring for women who end pregnancies for fetal anomalies (2nd trimester terminations through labor induction techniques). Nursing \& Health

Sciences, 7(2), 143.

Bishop, S. (2007). Doing taboo work: Nurses' experiences of caring for women having second trimester pregnancy terminations for fetal anomalies through labour induction. ProQuest Dissertations and Theses Global. (304807075). Retrieved from http://search.proquest.com/docview/30480 7075

British Columbia College of Nursing Professionals. (2019). https://www.bccnp.ca/Pages/Default.aspx Canadian Association of Schools of Nursing. (2017a). Entry to Practice Competencies for Nursing Care of the Childbearing Family for Baccalaureate Programs in Nursing. Retrieved from: https://www.casn.ca/wpcontent/uploads/2016/09/FINAL-
CHILDBEARING-FAMILYCOMPETENCIES-revised.pdf

Canadian Association of Schools of Nursing. (2017b) Registered Nurses Education in Canada Statistics 2015-2016. Retrieved from: https://www.casn.ca/wpcontent/uploads/2017/12/2015-2016-ENSFS-FINAL-REPORT-supressed-forweb.pdf

Canadian Institute for Health Information (CIHI). (2016). Induced abortions reported in Canada. Retrieved from: https://www.cihi.ca/en/induced-abortionsreported-in-canada-in-2016

Canadian Nurses Association. (2013). Registered nurses stepping up to transform health care. Retrieved from: https://www.cnaaiic.ca/ /media/cna/files/en/registered_nur ses_stepping_up_to_transform_health_car e_e.pdf

Canadian Nurses Association. (2017). Nurse Practitioners in rural and remote communities. Retrieved from: https://www.cna-aiic.ca/-/media/cna/pagecontent/pdf-en/nurse-practioners-in-ruraland-remote-communities-fact-sheet.pdf

Canadian Nurses Association. (2018). Nursing statistics. Retrieved from: https://www.cna-aiic.ca/en/nursingpractice/the-practice-of-nursing/healthhuman-resources/nursing-statistics

CBC News. (2009). Abortion rights: Significant moments in Canadian history. CBC News. Retrieved from: https://www.cbc.ca/news/canada/abortionrights-significant-moments-in-canadianhistory-1.787212

CIHI. (2017). Induced abortions reported in Canada in 2017. Retrieved from: https://www.cihi.ca/sites/default/files/doc ument/induced-abortion-2017-enweb.xlsx

College and Association of Registered Nurses of Alberta. (2019). https://www.nurses.ab.ca/

College of Nurses of Ontario. (2019). https://www.cno.org/

College of Nurses of Ontario (2017). What NPs should know about Mifegymiso. 
Retrieved from:

http://www.cno.org/en/news/2017/july-

2017/what-nps-should-know-aboutmifegymiso/.

College of Registered Nurses of Manitoba. (2019). https://www.crnm.mb.ca/

College of Registered Nurses of Prince Edward Island (2019). https://www.crnpei.ca/

Crenshaw, K. (1989). Demarginalizing the Intersection of Race and Sex: A Black Feminist Critique of Antidiscrimination Doctrine, Feminist Theory and Antiracist Politics. Chicago Legal Forum, 1(8), 139167.

Dunphy, C. (2018). The new face of the abortion debate. Chateleine. Retrieved from: https://www.chatelaine.com/living/thenew-face-of-the-abortion-debate/

Erdman, J. (2019). We cannot solve abortion pill prescription problems without rethinking our approach. The Globe and Mail. Retrieved from: https://www.theglobeandmail.com/opinio n/article-we-cannot-solve-abortion-pillprescription-problems-without-rethinking/

Glauser, W. (2018). Canada and US going in opposite directions on conscientious objection for doctors. CMAJ News. Retrieved from: https://cmajnews.com/2018/02/12/canadaand-us-going-opposite-directions-onconscientious-objection-for-doctors-cmaj109-5572/

Government of Canada. (1982). Constitution Act: Canadian Charter of Rights and Freedoms. Retrieved from: https://lawslois.justice.gc.ca/eng/const/page15.htmlGrant, K. (2019). Why the only abortion clinic on Vancouver Island has stopped offering surgical abortions. The Globe and Mail. Retrieved from: https://www.theglobeandmail.com/canada article-why-the-only-abortion-clinic-onvancouver-island-has-stopped-offering/

Guttmacher Institute. (2019). An overview of abortion laws. Author. Retrieved from: https://www.guttmacher.org/statepolicy/explore/overview-abortion-laws
Haney, C. (2011). Nursing identity and abortion work (Masters thesis). University of British Columbia. Vancouver, Canada. Retrieved from: https://pdfs.semanticscholar.org/36fd/91b 63edd1b2ab9becba286e38e8a41d971ed.p df

Harding, S. (1992). Rethinking standpoint objectivity: What is 'strong objectivity'? The Centennial Review, 36(3), 437-470.

Harris v. McRae, 448 U.S. 297 (1980). Retrieved from: https://supreme.justia.com/cases/federal/u s/448/297/

Health Canada. (2015a). Drug Product Database. Retrieved from: http://www.hc-sc.gc.ca/dhpmps/prodpharma/databasdon/indexeng.php

Health Canada. (2015b). Regulatory decision summary: MIFEGYMISO. Retrieved from: Retrieved from: https://hprrps.hres.ca/reg-content/regulatorydecision-summarydetail.php?lang=en\&linkID=RDS00294

Health Canada. (2017). MIFEGYMISO. Health Canada updates prescribing and dispensing information for Mifegymiso. Retrieved from: Retrieved from: https://www.healthycanadians.gc.ca/reca ll-alert-rappel-avis/hc-sc/2017/65034aeng.php

Kishen, M., \& Stedman, Y. (2010). The role of Advanced Nurse Practitioners in the availability of abortion services. Best Practice \& Research Clinical Obstetrics \& Gynaecology, 24(5), 569-578.

Liu, K., \& Dipietro Mager, N. (2016). Women's involvement in clinical trials: Historical perspective and future implications. Pharmacy Practice (Granada), 14(1), 708.

Mazure, C., \& Jones, D. (2015). Twenty years and still counting: Including women as participants and studying sex and gender in biomedical research. BMC Women's Health, 15(1), 94.

McFadden, R. (2013). Henry Morgentaler, 90, dies; Abortion defender. The New York 
Times. Retrieved from:

https://www.nytimes.com/2013/05/30/wor 1d/americas/henry-morgentaler-abortiondoctor-in-canada-dies-at-90.html

McLemore, M., \& Levi, A. (2011). Nurses and care of women seeking abortions, 1971 to 2011. Journal of Obstetric, Gynecologic \& Neonatal Nursing, 40(6), 672-677.

McTavish, L. (2015). Abortion in New Brunswick. Acadiensis, 44(2), 107-130.

Melchior, F. (2004). Feminist approaches to nursing history. Western Journal of Nursing Research, 26(3), 340-355.

Nash, E., Gold, R. B., Mohammed, L., \& Cappello, O. (2018). Policy trends in the States, 2017. Guttmacher Institute. Retrieved from. https://www.guttmacher.org/article/2018/ 01/policy-trends-states-2017

Norman, W. V. (2012). Induced abortion in Canada 1974-2005: Trends over the first generation with legal access. Contraception, 85, 185-91.

Nijhawan, N., \& McMillan, K. (2016). Keynote. Women's Legal Education and Action Fund Person's Day Breakfast, October 14, Halifax.

Norman, W. V., Guilbert, E. R., Okpaleke, C., Hayden, A. S., Steven Lichtenberg, E., Paul, M., White, K. O. \& Jones, H. E. (2016). Abortion health services in Canada: Results of a 2012 national survey. Canadian Family Physician, 62, e209-e217.

Norman, W.V., Hestrin, B., Dueck, R. (2014). Access to complex abortion care service and planning improved through a toll-free telephone resource line. Obstetrics and Gynecology International. doi: 10.1155/2014/913241.

Norman, W.V., \& Soon, J.A. (2016). Requiring physicians to dispense mifepristone: An unnecessary limit on safety and access to medical abortion. CMAJ. 188(1718):E429-E30.

Nova Scotia College of Nursing. (2019). https://www.nscn.ca/

Nurses for Sexual and Reproductive Health. (2019). Nsrh.org
Nurse Association for New Brunswick (2019). http://www.nanb.nb.ca/

Ordre des infirmières et infirmiers du Québec. (2019). https://www.ncsbn.org/Quebec.htm

Paepcke, J._(2018)._Nurse still healing 20 years after fatal abortion clinic blast. WVTM. Retrieved from: https://www.wvtm13.com/article/nursestill-healing-20-years-after-fatal-abortionclinic-blast/15918754

Parker, A., Swanson, H., \& Frunchak, V. (2014). Needs of labor and delivery nurses caring for women undergoing pregnancy termination. Journal of Obstetric, Gynecologic, \& Neonatal Nursing, 43(4), 478-487.

Planned Parenthood v. Danforth, 428 U.S. 52 (1976). Retrieved from: https://supreme.justia.com/cases/federal/u $\mathrm{s} / 428 / 52 /$

Price, S., Doucet, S., \& McGillis Hall, L. (2014). The historical social positioning of nursing and medicine: Implications for career choice, early socialization and interprofessional collaboration. Journal of Interprofessional Care, 28(2), 103-109.

R v Morgentaler (1988) 1 SCR 30 Retrieved from: https://scc-csc.lexum.com/scccsc/scc-csc/en/item/288/index.do

Registered Nurses Association of the Northwest Territories and Nunavut. (2019). https://www.rnantnu.ca/

Roe v. Wade, 410 U.S. 113 (1973). Retrieved from Justia Legal Resources: https://supreme.justia.com/cases/federal/u s/410/113/

Saskatchewan Registered Nurses Association. (2019). https://www.srna.org/

Sedgh, G., Bearak, J., Singh, S., Bankole, A., Popinchalk, A., Ganatra, B... Alkema, L. (2016). Abortion incidence between 1990 and 2014: Global, regional, and subregional levels and trends. The Lancet, 388(10041), 258-267.

Shaw, D. \& Norman, W. V. (2019). When there are no abortion laws: A case study of Canada. Best Practice \& Research Clinical Obstetrics \& Gynaecology, 
https://doi.org/10.1016/j.bpobgyn.2019. $\underline{05.010}$

Sheinfeld, L., Arnott, G., El-Haddad, J., \& Foster, A. (2016). Assessing abortion coverage in nurse practitioner programs in Canada: A national survey of program directors. Contraception, 94(5), 483488.

Stack, L. (2015). A brief history of deadly attacks on abortion providers. The New York Times. Retrieved from: https://www.nytimes.com/interactive/20 15/11/29/us/30abortion-clinicviolence.html

Statistics Canada. (2019). Live births by month. Retrieved from: https://www150.statcan.gc.ca/t1/tbl1/en/tv action?pid=1310041501

Stettner, S. (2016). Without apology. Edmonton: Athabasca University Press. Retrieved from:

https://uwspace.uwaterloo.ca/bitstream/ha ndle/10012/11165/Stettner 2016-

Without_Apology.pdf? sequence $=1 \&$ isAll owed $=y$

The Canadian Press. (2018) Nova Scotia launches toll-free hotline for women considering abortion. CBC News. Retrieved from: https://www.cbc.ca/news/canada/novascotia/toll-free-phone-line-womenpregnancy-abortion-1.4516242

Tremblay v Daigle [1989] 2 S.C.R. 530

Retrieved from: https://scccsc.lexum.com $/$ scc-csc $/$ scccsc/en/item/515/index.do

Van Herk, K., Smith, D., \& Andrew, C. (2011). Examining our privileges and oppressions: Incorporating an intersectionality paradigm into nursing. Nursing Inquiry, 18(1), 29-39.
Veiga, M., Lam, M., Gemeinhardt, C., Houlihan, E., Fitzsimmons, B., \& Hodgson, Z. (2011). Social support in the post-abortion recovery room: Evidence from patients, support persons and nurses in a Vancouver clinic. Contraception, 83(3), 268-273.

Vogel, L. (2017). Doctors, pharmacists push back on medical abortion rules. CMAJ News. Retrieved from: https://cmajnews.com/2017/03/09/doctors -pharmacists-push-back-on-medicalabortion-rules-109-5406/

Wall S. (2007). Nurses' engagement with feminist/poststructuralist theory: (Im)possibility, fear, and hope, Thirdspace: A Journal of Feminist Theory \& Culture; 7(1), 37.

Weitz, T., Taylor, D., Desai, S., Upadhyay, U., Waldman, J., Battistelli, M., \& Drey, E. (2013). Safety of aspiration abortion performed by nurse practitioners, certified nurse midwives, and physician assistants under a California legal waiver. American Journal of Public Health, 103(3), 454461.

Women's Legal Education and Action Fund (LEAF). (2016). LEAF and AANPEI welcome announcement that PEI government will end its discriminatory abortion policy. Retrieved from: https://www.leaf.ca/leaf-and-aanpeiwelcome-announcement-that-peigovernment-will-end-itsdiscriminatory-abortion-policy/

World Health Organization (2018). Global Abortion Policies Database. Retrieved from: https://abortion-policies.srhr.org Yukon Registered Nurses Association. (2019). https://yukonnurses.ca/ 